\title{
Strength assessment of stiffened blast walls in offshore installations under explosions
}

Jung Min Sohnª, Sang Jin Kim ${ }^{\mathrm{b}}$, Jung Kwan Seo ${ }^{\mathrm{b}}$, Bong Ju Kim ${ }^{\mathrm{b}}$ and Jeom Kee Paik ${ }^{\mathrm{b}, \mathrm{c}, *}$

${ }^{a}$ Korea Research Institute of Ships \& Ocean Engineering, Daejeon, Korea

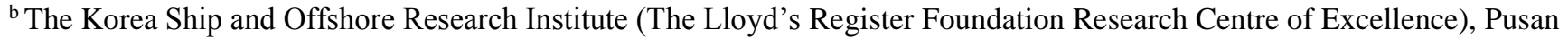 \\ National University, Busan, Korea \\ ${ }^{\mathrm{c}}$ Department of Mechanical Engineering, University College London, London, UK
}

\begin{abstract}
Offshore installations are exposed to hydrocarbon explosion and/or fire accidents. Especially, explosions lead serious damages to human, safety and environment. To minimize and prevent the damage from explosions, blast walls are generally installed in oil and gas production structures. Typical blast walls are divided into flat, corrugated, and stiffened type of blast walls. Among of them, corrugated blast walls are frequently used for reasons such as construction, cost, and energy absorption etc.

However, it has been known that corrugated type of blast wall buckles between web and flange under the explosion loads, and it loses its stiffness. It means that the buckling phenomenon of blast wall is closely related to the structural strength. This study focuses on the structural characteristics of blast wall under quasi-static and dynamic (explosion) loads according to with or without flat-plated stiffener. Finally, it could be concluded that flat type of stiffener is located at the buckling region to delay the buckling and improve the strength of blast walls.
\end{abstract}

\section{Keywords}

Offshore installations, corrugated blast wall, buckling, stiffened blast wall, nonlinear finite element analysis

\section{Introduction}

Energy shortages are transferring the world's attention towards oil and gas development in deep and ultradeep ocean, as shown in Figure 1. The performance of deep water and ultra-deep water $(>1,500 \mathrm{~m})$ technology 
has been remarkable increased over the last 15 years. Deepwater production started in the 1990s, rapidly reaching 1.5 million b/d by 2000, and it is expected the production is at least $\$ 20$ billion for offshore fields over the next five years.

Figure 1. World offshore oil production: Onshore vs. offshore (Energy and Capital, 2014).

Along with this, the accidents have drew the attention of the offshore industry to the damage that could arise in the event of an explosion and fire on an offshore platform. Explosion is one of the major hazards with potentially severe consequences to the life and health of human, environmental pollution, direct and/or indirect economic losses, and deterioration of the security of energy supply. According to the DNV·GL (2007), release of fluid or gas and explosion accidents record major accidents with severe damage from 1970 to 2007. Those accidents killed 352 people and injured 173 from 1971 to 2014 (OGP, 2010). Especially, the topside structures on offshore platforms are exposed to hydrocarbon explosions and/or fire accidents. It's because that the process area of an offshore oil and gas platform is very compact with a high degree of congestion and confinement due to space limitations and environmental conditions.

However, accidental events can in some cases be avoided by taking appropriate measures to eliminate the source of the event or by bypassing and overcoming its structural effects. Designers can choose among avoiding a hazard (e.g. by taking special preventive measures such as operational restrictions), minimizing the (structural) consequences of the considered hazard (e.g. by implementing protective measures) or designing for the hazard.

Figure 2. Typical blast walls on offshore installations (Mech-Tool Korea, 2014).

In the present study, a blast wall is chosen for the design option. Blast walls are integral structures in typical offshore installations to protect personnel and safety critical equipment by preventing the escalation of events due to hydrocarbon explosions, as shown in Figure 2. The blast walls are expected to retain their integrity against any explosion loading. The primary objective of this study is to suggest design guidance to estimate the structural behavior of the blast wall using nonlinear finite element methods under explosion loads obtained from explosion 
simulation. In addition, new design concept of blast walls, which takes practicable advantages in the industry, is introduced to prevent web buckling or absorb impact energy by installing stiffened panel. This study will be very useful as a practical guideline for structural response analysis of blast walls in offshore installations.

\section{Literature reviews}

In the past, design explosion loads are derived from the worst credible event assuming gas cloud of maximal extent with stoichiometric composition ignites at the worst time and in the worst position. Ultimate peak overpressure derived using this approach is far too large to be accommodated by the structure and it does not represent reality (Høiset et al., 1997). Also, the structural behavior is represented with single degree of freedom (SDOF) methods using equivalent beam. However, the structural response can be characterized by a single stiffness (resistance curve) and the loading applied as a single time varying quantity (HSE, 2006a). Lawver et al. (2003) addressed that the equivalent SDOF method is accurate for small deflection. Nevertheless, it is unable to predict the large deflection because it could not capture local bending.

In the light of improvements in modelling of explosion loading and developing technique for the finite element method, it has now become apparent predicting structural response subjected to explosion loads without simplifying assumption. Johnson et al. (2002) described an experimental project and modelling work undertaken to provide a more realistic representation of the risks posed by gas explosions in offshore platforms. Pula et al. (2006) reviewed the existing consequence models to perform a consequence assessment for an offshore platform by simulating four different scenarios. Czujko (2001) provided guidance for the design and strength assessment of topside structures against the effects of accidental gas explosions. Furthermore, integrated research for the blast loading obtained from FLACS is used as input for detailed finite element analysis (FEA) of structures using the ANSYS/LS-DYNA (2014) code. Paik and Czujko (2010) produced documented procedures and guidelines for use

in the assessment of gas explosion and fire actions, the resulting consequences for FPSO topside structures. Taveau and Moras (2012) performed 3-D gas explosion simulation using FLACS to define a typical pressure load profile to apply on the inner side of the tank shell. Then, the structural response of the tank (deformation and displacement), under the loading conditions previously obtained, has been computed with ANSYS/LS-DYNA. Czujko and Paik (2014) presented a reliability based robustness assessment method for structures designed using 
Accidental Limit State to resist hydrocarbon explosion loads. It is also defined frequency of exceedance of design blast load and wall damage.

Regarding to the study on the dynamic characteristic of blast walls, many studies regarding to the structural response of the corrugated blast walls (HSE, 2003; HSE, 2004; HSE 2006b). These papers only focus on the structural strength of general blast walls. However, several studies tried to suggest new type of blast walls by showing advantages of improving their structural integrity. Louca et al. (1996) compared results on the response of a typical blast wall and a tee-stiffened panel. The effect of restraint to the stiffener was most dramatic in that the overall buckling. Wigaya and Kim (2011) studied the FE analysis of the round and v-type blast walls under blast loadings. They concluded that V-stiffeners are structurally more effective than round one, notwithstanding the higher manufacturing costs. This study also suggests non-traditional blast walls to enhance structural strength regardless of massive stiffeners and working time to bending and welding.

\section{Design process for blast walls}

This section describes how explosion accidents are treated and designed in several design guidance. In addition, appropriated design process of structural assessment for blast walls is established. API (2014) states that the assessment process intended to be a series of evaluations of specific events that could occur for the selected platform over its intended service life and service functions. Detailed design guidelines and information for consideration of blast events on offshore platform are stated in section 18.7 in API (2014) code.

According to ISO (2013), offshore structures and their structural components shall be designed to satisfy particular limit states. ISO (2007) suggest a two-stage procedure for design of fixed steel offshore structures. First, the structure is designed for the accidental situation involving the hazard considered. After the hazardous event has occurred, check the after damage design situation in relation to specified environmental actions. It is also noted that if damage is indicated, a reliable prediction of the nature and the extent of the damage normally requires the application of nonlinear structural analysis methods.

Based on design guidance, this study suggests an advanced practical design process of blast walls using nonlinear finite element method, as shown in Figure 3. This procedure is specialized in the design of blast walls and detailed procedure for nonlinear FE analysis is explained. 
Figure 3. Advanced design process of blast wall under explosion loads.

First, action analysis is performed to determine explosion loads. Various types of explosion models are available to predict blast loads. Explosion design pressure could be determined based on the probability of an explosion overpressure exceeding a particular value or maximum value. After that, explosion scenarios, such as the pressure-time curves for overpressure or drag loads, are built. Consequently, action effects analysis is conducted to determine the structural response or its damage in a structure in response to a given set of actions. Nonlinear FE analysis or simplified method is suggested as an option to analyze the structural response under blast loadings. However, this study recommends that nonlinear FE analysis should be used under high overpressure considering both of material and geometric nonlinearities. The results in FE analysis are capable of giving a better overall picture in terms of the response of blast walls such as connection failure, buckling, or membrane effects. Important things in FE analysis, the results must be validated in comparison with experimental or analytical results. Finally, Pressure-Impulse curves are used to assess the structural integrity of blast walls combining together with maximum explosion load level. This study suggests the deformation limits based on effective plastic strains about 1, 5 and $10 \%$ in nonlinear static analysis for reflecting the elastic, elasto-plastic and plastic range. In addition, ultimate explosion loads are investigated based on strain limit of 5\%. All action or action effects shall be considered to ensure the ultimate explosion loads are not exceeded.

\section{Nonlinear structural response of stiffened blast walls}

\subsection{Finite element model}

Figure 4 shows the layout of the blast walls with its top and bottom connections. Connection should be assessed for their ability to allow structural component to develop their full plastic strength. The large deformation occurs in the blast walls, therefore finite model should be consider the geometrical nonlinearity effects including member shrinkage and membrane forces. In the present study, ANSYS/LS-DYNA (2014) is applicable Finite-Element software to simulate and analyze highly nonlinear physical phenomenon. Isoparametric quadrilateral elements with four nodes and six degrees of freedom per node were used to analyze thin- 
to moderately-thick shell structure like as the corrugated steel plate elements (Paik, 2011; Kim et al., 2011). Plate girder is consisted of fully integrated quadratic 8 node element with nodal rotation to simulate both bending and large strain deformation behavior with material nonlinearity.

Figure 4. A detailed drawing of blast wall with connection part.

Figure 5(a) shows web buckling of unstiffened corrugated blast walls. It shows that web and flange buckling occur at the center of blast wall. A flat plate was installed at the spot where buckling occurred, as shown in Figure 5(b), to enhance the strength of corrugated blast walls. This study investigates how can it delay the buckling occurs by installing the flat plate. The same modelling techniques determined in Sohn et al. (2013) were adopted to assess the nonlinear structural response characteristics of stiffened blast walls. Modelling of welded joints is important to improve the quality; however, this study only focuses on the effect of flat plate on structural strength. It is also examined structural strength depending on the flat plate thickness $\left(\mathrm{t}_{\mathrm{s}}\right)$.
(a) Buckling shape
(b) Location of flat plate

Figure 5. Location of buckling point of corrugated blast wall.

\subsection{Explosion loads}

To simplify the structural analysis, the time history of the panel load around its peak was idealized as a triangular impulse. The triangular type was defined as the time history of the structural response to a symmetric triangular impulse of a short duration, from which it is possible to generate the triangular impulse of the duration and the rise time, which is an integer multiple of the short duration. The maximum response time was then taken as half of the duration. The area under the triangular curve which can be identified as demand energy. The explosion loads applied to the blast walls is a uniformly distributed and normal to the surface.

\subsection{Mesh size}


As the thin steel plate elements of blast walls are subjected to local buckling and the plates and stiffeners to in- and out-of-plane buckling effects, the element chosen must be capable of modelling these buckling phenomena and their associated behavior. Therefore, sufficiently small elements are required in a model to ensure that the results of an analysis are not affected by changing the size of the mesh. A curve of a critical result parameter was required in a specific location to establish mesh convergence. Plus, it was plotted against some measure of mesh density, as shown in Figure 6. The mesh size is varied in the center of blast wall for time efficiency. The convergence studies indicated that an approximate element size of $10 \times 10 \mathrm{~mm}$ (width $\times$ breadth) for corrugated blast walls did not require the needs for excessive computation time. It is also important to aware the deformation pattern using a fine mesh structure to ensure correct buckling and response in the wall.

Figure 6. Mesh convergence of the blast walls.

\subsection{Material properties}

The material of blast walls was stainless steel, which is commonly used in the industry. Also, stainless steel blast walls have been introduced in the FABIG (1999) report. It has an excellent mechanical property, which exhibits considerable energy absorption and ductility characteristic. In addition, the advantages include good fire and corrosion resistance properties (HSE, 2004). The used material model in the ANSYS/LS-DYNA (2014) is a "Material type 24 piecewise_linear_plastic". It is an isotropic, piecewise linear plastic material. In order to represent the plastic behavior in a Nonlinear FE analysis, the behavior up to the maximum stress should be represented using the engineering stress-strain relationship. It is also important that the yield stress of material explosion loads is stronger than the yield stress when static load is applied. Therefore, the strain-rate effect should be considered for dynamic structural analysis (Langdon and Schleyer, 2004). One of the methods for considering dynamic effect is Cowper-Symonds equation. Cowper and Symonds (1957) suggested Equation (1) to consider the strain-effect of material.

$$
\frac{\sigma_{Y d}}{\sigma_{Y}}=1.0+\left(\frac{\dot{\varepsilon}}{C}\right)^{1 / q}
$$


where $\mathrm{C}$ and $\mathrm{q}$ are coefficients to be determined on the basis of the test data shown in Figure 7. It is evident that coefficients $\mathrm{C}$ and $\mathrm{q}$ are dependent on the material type, among other factors.

Figure 7. Dynamic yield strength (normalized by the static yield strength) versus strain rate.

\subsection{Boundary conditions}

FE models of the blast walls including corrugated profile and supporting structure are developed. Figure 8 shows the FE model together with the boundary conditions. Nodes in supporting plate girder are connected to one's in the corrugated profile to consider the weld joint. The boundary conditions applied to the model should not make significant errors in the structural response. In addition, it should be reflected the realistic support conditions to assess the capacity of blast wall, as shown in Figure 8. However, initial stress was not considered in the present study.

Figure 8. Applied boundary conditions.

\subsection{Static structural response}

The major objective of the static analysis is to assign the pushover curves. It shows the static capacity and its corresponding response of blast wall. The pressure is increased until collapse of the wall. Increase in load capacity caused by development of membrane forces. End supports are related to restrain against axial forces. Nonlinear static analysis was performed to determine the thickness of flat plate by establishing the relationship between loads and the induced response under pressure loading. Figure 9 shows the ultimate static strength capacity of stiffened blast wall on the basis of developed pushover curves. It compares structural capacity depending on the installing flat plat or not. Static strength is increased about $3 \%$ and plastic deflection is increased about $20.5 \%$ by installing $10 \mathrm{~mm}$ flat plate.

Figure 9. Static push-over analysis of unstiffened and stiffened blast wall. 
Figure 10 compares the push over analysis curves and it can cover the reason for enhancing ultimate strength and plastic deflection limit. They are identically same curves until reaching the ultimate strength of unstiffened blast wall. However, there is shown the distinction in post- ultimate. It means that stiffened blast wall reinforce the capacity of blast wall by absorbing more strain energy then unstiffened blast wall. The reason for the results are the stiffener can play a role for preventing overall bending within a certain response, it can delay structural damage by installing the flat plate.

Figure 10. Comparison of pushover curves between stiffened and un-stiffened blast wall.

Figure 11 shows the nonlinear static response of stiffened blast wall. The plastic strain is concentrated at two regions instead of the center of blast walls due to having more stiffness. As the deflection increases, the flat plate can no longer prevent the buckling formation. Finally, buckling occurs at the upper part of flat plate stiffener due to the loss of upper connection support. It can be concluded that blast wall has a slightly high structural capacity by installing the flat plate, so, it can delay the moment which buckling occurs.

$\begin{array}{ll}\text { (a) Wall damage at } 1 \% \text { plastic strain } & \text { (b) Wall damage at } 10 \% \text { plastic strain }\end{array}$

Figure 11. Nonlinear static responses of stiffened blast wall.

\subsection{Dynamic structural response}

Recently, it has been addressed that the characteristics of offshore hydrocarbon explosion have shown the possibility of overpressures of several bars in a typical offshore module (API, 2014; HSE, 2004). Therefore, the design of blast walls under extreme loading level is likely to involve large plastic deformations, weld tearing, and possible contact with adjacent plant or structural components. In order to consider the plastic condition, dynamic structural response should be known to design the blast walls. In the present study, a series of ANSYS/LS-DYNA (2014) computations were undertaken on the basis of the procedure described in the previous sections to assess the performance of the blast walls under explosion loading actions. Considered explosion loads are as follows:

- Peak pressure $\left(p_{\text {peak }}\right): 0.7,1.0,1.5,2.0,2.5$ bar 
- Impulse ( $I$ ): 0.001, 0.01, 0.02, 0.025, 0.03, 0.035, 0.045, $0.06 \mathrm{bar} \cdot \mathrm{s}$

The dynamic structural response characteristics of stiffened blast walls with strain effect were investigated using ANSYS/LS-DYNA (2014). Figures 12 and 13 show maximum and permanent deflection of stiffened blast walls. In the present study, the center points are defined as the monitoring point. Maximum deflection $\left(w_{\max }\right)$ is defined as the maximum value and permanent deflection $\left(w_{p}\right)$ is the average value after the duration time. Out-ofplane deflection increased as higher impulse or/and peak pressure was applied. This tendency should relieve the increase of the impulse. The deflection increases as a high pressure is applied to the impulse/dynamic regions, whereas the permanent deflection converges at a certain value in the quasi-static regions. Interest thing is that, there is no quite difference between 2.0bar and 2.5bar. It is closely related that installing flat plate in blast walls is no longer prevent buckling under high pressure.

Figure 12. Maximum deflection of stiffened blast walls with varying peak pressure.

Figure 13. Permanent deflection of stiffened blast walls with varying peak pressure.

\section{Structural damage}

\subsection{Design criteria}

The purpose of this section is to give information what should be considered when analyzing blast walls under explosion loads. The function of blast walls is to separate parts of a platform so that an explosion within one are will not affect adjacent areas. It is important that blast walls should secure safe area without being breached. Therefore, deformation may be an essential feature of the blast walls design. Deformation limits can be based on a maximum allowable strain or an absolute displacement. Structural steels used offshore have sufficient toughness and are not significantly limited in strain capability at the high strain rates associated with explosion response. Reductions in strain limits can be required. For typical structural steel grade, the principal tensile strains from a FE analysis should be limited to about 5\% (API, 2014; ISO, 2007). In the present study, effective plastic strain 
limits in static structural response are used to assess the dynamic structural response of blast walls. The effective plastic strain about 1 , and $10 \%$ is selected as strain limit to suggest allowable deflection of blast walls.

\subsection{Pressure-impulse curves}

To facilitate the determination of the deflection limits, developed the Pressure-Impulse design curves are used. It can develop by combining the applied pressure and impulse associated with an explosion and the maximum structural response. Figure 14 shows the drawn pressure-impulse design curves using computation results. It compares the effect of installing the flat plate between the presence and absence of blast walls with $10 \mathrm{~mm}$-flatstiffener. As shown in the Figure 14, it consists of three categories, i.e. impulse sensitive range (impulsive loading region), dynamic range (dynamic loading region), and pressure sensitive range (quasi-static loading region).

In the present study, effective plastic strain limits in static structural response are used to assess the dynamic structural response of blast walls. The effective plastic strain about 1 , and $10 \%$ is selected as strain limit to suggest allowable deflection of blast walls. The effective plastic strain with $1 \%$ means that the structural response in in elastic regime, while the one with $10 \%$ presents the structural characteristic is in plastic limits.

According to the Figure 14, the effect of installing the flat plate and the stiffened plate thickness was considerable in the lower bound. However the effectiveness of the flat plate is diminished in dynamic sensitive region at upper bound limits. But it became marginal effect to the impulse sensitive region. It can be concluded that installing flat plate postpone the occurrence of buckling, however, it is not enough to prevent buckling.

Figure 14. Proposed Pressure-Impulse curves of stiffened blast walls.

To investigate the structural behavior depending the design gas explosion loads, actions are obtained from established exceedance curves, which was introduced by Paik and Czjuko (2010), are applied to the P-I curves. Figure 15 and Table 1 summarize structural deflection depending on applied explosion loads. Two load levels were considered; risk acceptable level and pessimistic case. The former is defined as the frequency of $10^{-4}$ exceedance per year, while the latter is the maximum value occurred in several locations. Maximum value is associated to a very low frequency. In addition they are marked in the Figure 15 that can easily recognize load 
generation position and integrity of blast wall at the specific loads. It means that if design explosion loads is applied under lower bound, the structural behavior is elastic, if they are in between lower and upper bound, the permanent deflection occurs but structure is still safe. However, it is over the upper bound, the structure could not resist the explosion loads. According to Table 1, this blast wall is sufficiently safe for a return time of 10,000 year. However, it is important to remember the possibility of the occurrence of some high peak pressure with high impulse which causes high structural damage. Particularly, process deck has high consequence due to equipment for oil and gas separators, pumps, compressors, etc. These design diagram should utilize the decision making whether installing high structural capacity blast wall or not, or to secure a sufficient distance between the blast wall.

Figure 15. Proposed Pressure-Impulse curves of stiffened blast wall with specific explosion load level.

Table 1. Structural damage for stiffened the blast walls.

\subsection{Effective plastic strain}

Blast walls' strengthening was performed by carbon steel bonded to column flanges. This made the increased the end reactions with increasing explosion loads, it results in the welded connection the weak link and increase the plastic strain of the wall. Table 2 summarized the plastic strain for the center and closed part to connections of blast wall after decaying explosion loads. Acceptance criteria for blast walls are also defined as functional requirement by determine maximum allowable plastic strains. In this study, plastic strain limit was assumed as $5 \%$. On the basis of Table 7.2, 2.5 bar with 0.025 bar.s, 2.0 bar with 0.026 bar.s and 1.5 bar with 0.032 bar.s are ultimate explosion profile of this blast walls.

Table 2. Effective plastic strain for connections.

\section{Concluding remarks}

This study presents an advanced practical design process of blast walls of offshore installations using nonlinear FE analysis under explosion loads and its application is presented. Nonlinear static and dynamic 
analysis are carried out for stiffened blast walls and related modelling technique was presented in detail. Finally, Pressure-Impulse curves with effective plastic strain limit are used to assess the structural damage at the target frequency obtained from explosion simulations. In addition, the ultimate explosion loads are determined based on limit strain capacity. The results obtained from this study can be summarized as follows.

- Design guidance for estimating the structural behavior of blast wall integrating nonlinear finite element analysis and explosion simulation,

- Detailed nonlinear structural analysis is performed to assess the structural damage using Pressure-Impulse design curves,

- The application of non-conventional shape blast walls were introduced to prevent web buckling and It is shown that it helps to delay the buckling phenomena, however, it could not resist the buckling.

These insights should be a useful guide for the safer design of blast walls in offshore installations for explosion loads.

\section{Acknowledgment}

This research was supported by Leading Foreign Research Institute Recruitment Program through the National Research Foundation of Korea (NRF) funded by the Ministry of Science, Ict \& future Planning (MSIP) (Grant no.: 2014040731).

\section{References}

ANSYS/LS-DYNA. 2014. User's manual (Version 14.5). Pennsylvania (PA): ANSYS Inc.

API. 2012. API-RP 2FB: design of offshore facilities against fire and blast loading. Washington (DC): American Petroleum Institute.

API. 2014. API-RP 2A: recommended practice for planning, designing and constructing fixed offshore platforms - working stress design foreword. Washington (DC): American Petroleum Institute. 
Cowper G, Symonds PS. 1957. Technical report 28: strain-hardening and strain-rate effects in the impact loading of cantilever beams. Rhode Island (RI): Department of Applied Mathematics. Brown University.

Czujko J. 2001. Design of offshore facilities to resist gas explosion hazard: engineering handbook. Trondheim (Norway): CorrOcean ASA.

Czujko J, Paik JK. 2014. A new method for accidental limit states design of thin-walled structures subjected to hydrocarbon explosion loads. Int: Proceedings of the International Conference on Thin-Walled Structures, 2014 September 28 - Octoer 2 October; Busan, Korea.

DNV·GL. 2007. Worldwide offshore accident databank. Oslo (Norway): Det Norske Veritas.

Energy and Capital. 2014. A graph of onshore vs. offshore oil production. http://www.energyandcapital.com/articles/offshore-oil-boom/4193.

FABIG. 1999. Technical note 5: Design guide for stainless steel blast walls. Berkshire (UK): Fire and Blast Information Group.

Høiset S, Hjertager BH, Solberg T, Malo KA. 1997. Statistical estimation of loads from gas explosions. Journal of Loss Prevention in the Process Industries. 10(4): 271283.

HSE. 2003. Research report 124: Pulse pressure testing of 1/4 scale blast wall panels with connections. London (UK): Health and Safety Executive.

HSE. 2004. Research report 146: analysis and design of profiled blast walls. London (UK): Health and Safety Executive.

HSE. 2006a. Research report 435: improved simplified response methods to blast loading. London (UK): Health and Safety Executive.

HSE. 2006b. Research report 404: pulse pressure testing of 1/4 scale blast wall panels with connection (Phase II). London (UK): Health and Safety Executive.

ISO. 2007. ISO 19902: petroleum and natural gas industries - fixed steel offshore structures. Geneva (Switzerland): International Organization for Standardization.

ISO. 2013. ISO 19900: petroleum and natural gas industries - general requirements for offshore structures. Geneva (Switzerland): International Organization for Standardization. 
ISO. 2014. ISO 19901-3: petroleum and natural gas industries - Specific requirements for offshore structures part 3: topsides structure. Geneva (Switzerland): International Organization for Standardization.

Johnson DM, Cleaver RP, Puttock JS, Van CJ. 2002. Investigation of gas dispersion and explosions in offshore modules. Int: Proceedings of Offshore Technology Conference, 2002 May 6-9; Houston, TX.

Kim BJ, Kim BH, Sohn JM, Paik JK, Seo JK. 2011. A parametric study on explosion impact response factors characteristics of offshore installation's corrugated blast wall. Journal of Korean Society of ocean Engineering. 26(3):46-54 (In Korean).

Langdon GS, Schleyer GK. 2004. Unusual strain rate sensitive behaviour of AISI 316L austenitic stainless steel. Strain Analysis for Engineering Design. 39(1):71-86.

Lawver D, Daddazio R, Vaughan D, Stanley M and Levine H. 2003. Response of AISC steel column section to blast loading. Proceeding of American Society of Mechanical Engineers, 2003 July 20 - 24; Ohio, USA.

Louca LA, Punjani M, Harding JE. 1996. Non-linear analysis of blast walls and stiffened panels subjected to hydrocarbon explosions. Journal of Constructional Steel Research. 37(2):93-113.

Mech-Tool Korea Inc. 2014. A photo of blast walls. http://www.mechtoolkorea.com.

OGP. 2010. Report No. 434-17: risk assessment data directory: Major accidents. London (UK): International Association of Oil \& Gas Producers.

Paik JK. 2011. Report No. EFEF-04: explosion and fire engineering of FPSOs (Phase III): nonlinear structural consequence analysis. Busan (Korea): The Korea Ship and Offshore Research Institute. Pusan National University.

Paik JK, Czujko J. 2010. Report No. EFEF-03: explosion and fire engineering of FPSOs (Phase II): definition of design explosion and fire loads. Busan (Korea): The Korea Ship and Offshore Research Institute. Pusan National University.

Pula R, Khan FI, Veitch B, Amyotte PR. 2006. A grid based approach for fire and explosion consequence analysis. Process Safety and Environmental Protection. 84(2):79-91.

Sohn JM, Kim SJ, Kim BH, Paik JK. 2013. Nonlinear structural consequence analysis of FPSO topside blast walls. Ocean Engeering. 60:149-162. 
Taveau J, Moras B. 2012. Explosion of fixed roof atmospheric storage tanks, part 3: Gas explosion and structural response simulations. Process Safety Progress. 31(3):230-239.

Wijaya C, Kim BT. 2011. FE analysis of unstiffened and stiffened corrugated panels subjected to blast loading. Journal of Mechanical Scienec and Technology. 25(12):3159-3164.

\section{Figures}

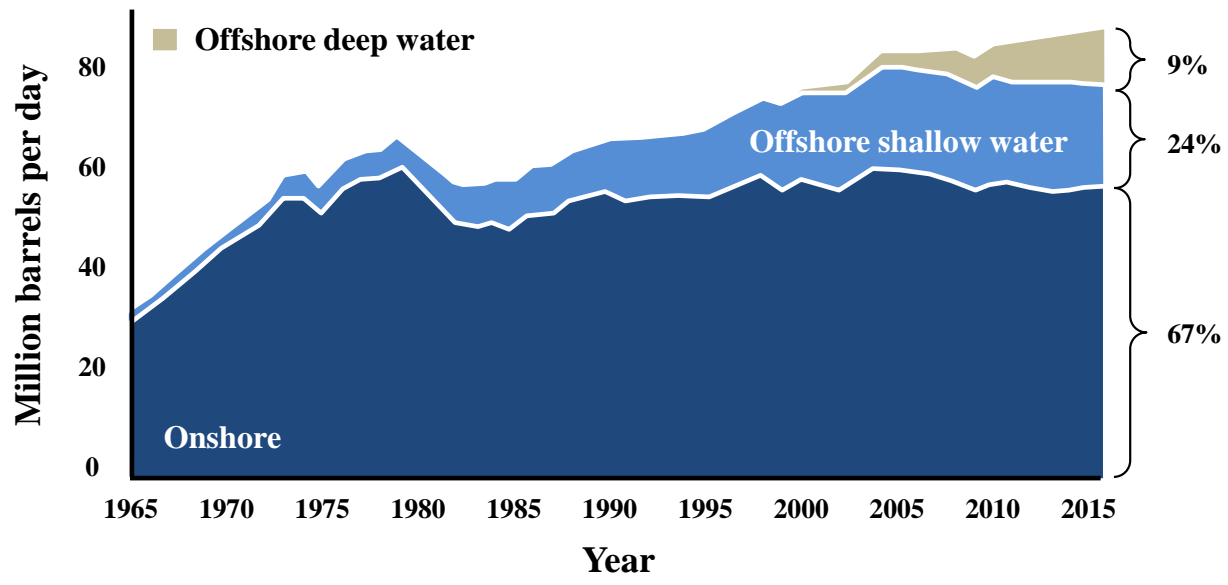

Figure 1. World offshore oil production: Onshore vs. offshore (Energy and Capital, 2014).

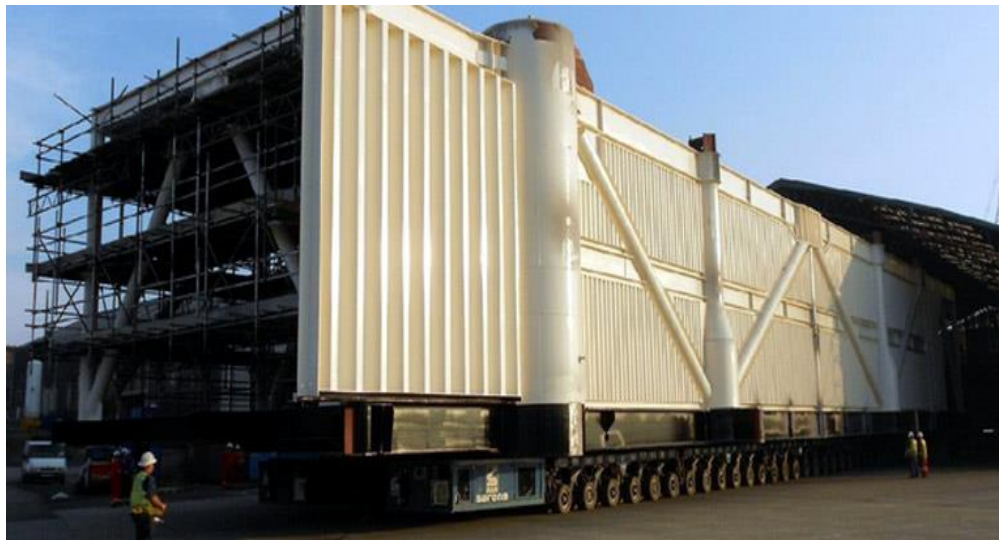

Figure 2. Typical blast walls on offshore installations (Mech-Tool Korea, 2014). 


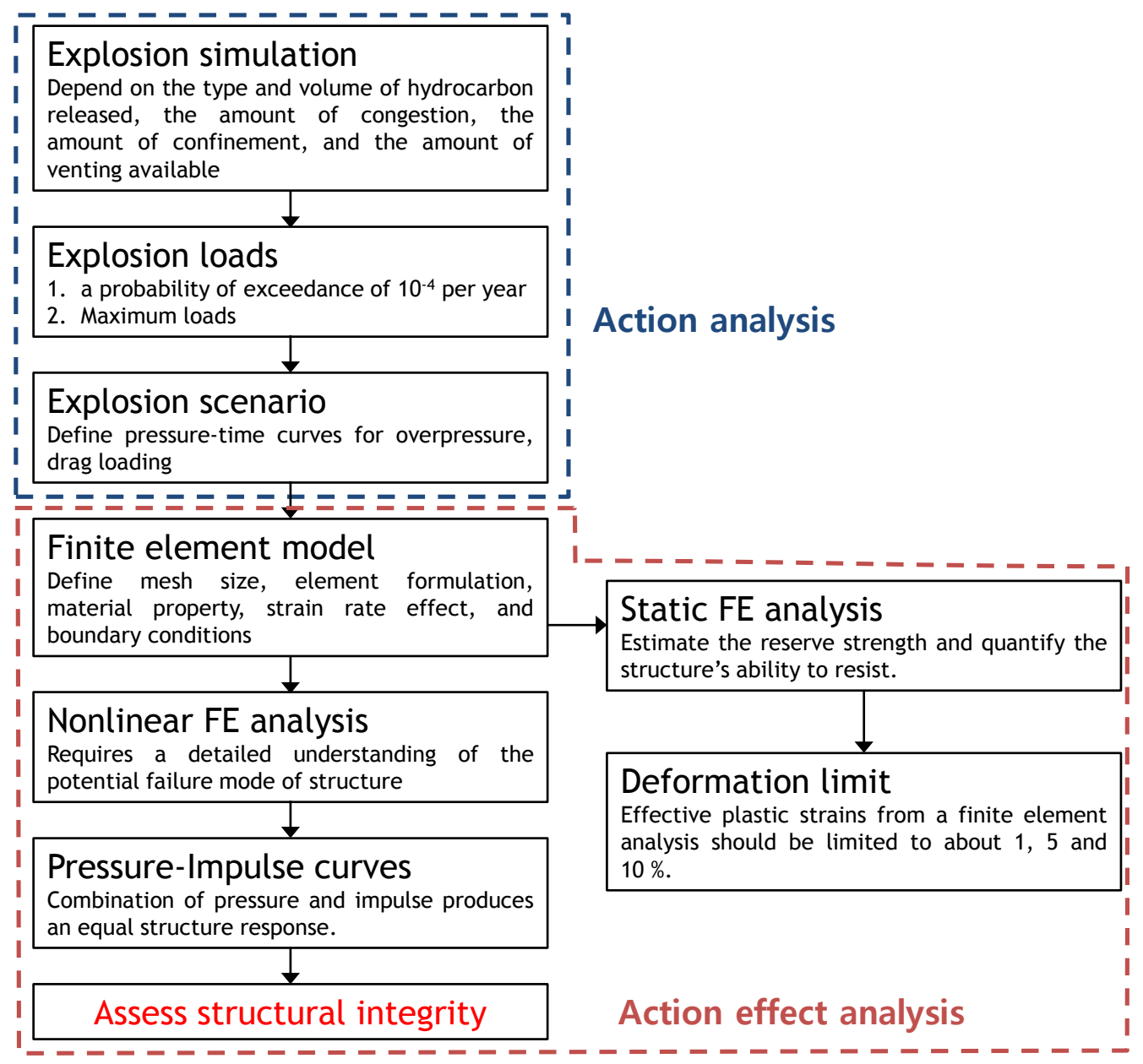

Figure 3. Advanced design process of blast wall under explosion loads.
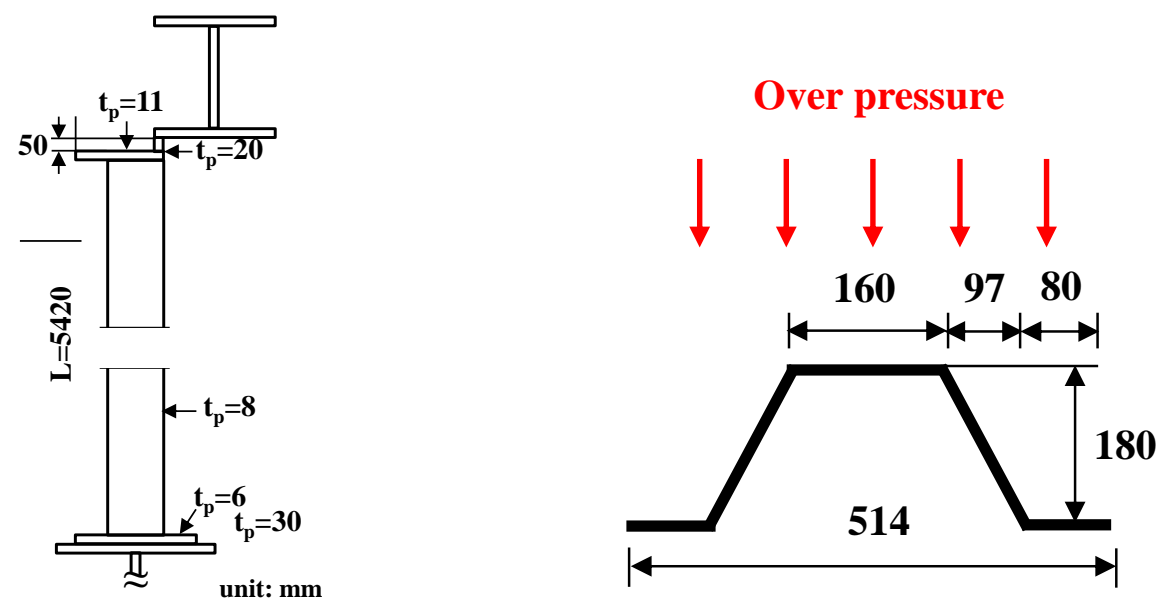

Figure 4. A detailed drawing of blast wall with connection part. 


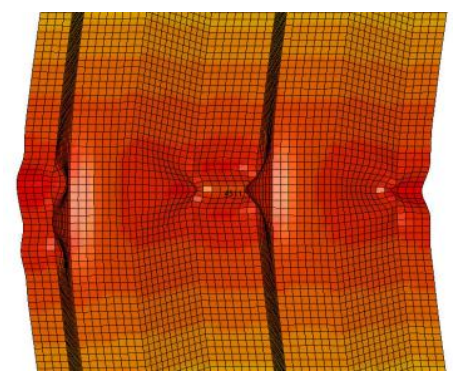

(a) Buckling shape

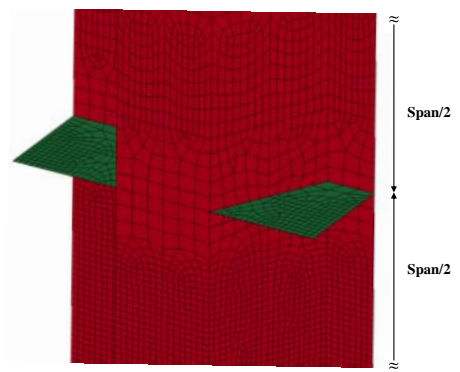

(b) Location of flat plate

Figure 5. Location of buckling point of corrugated blast wall.

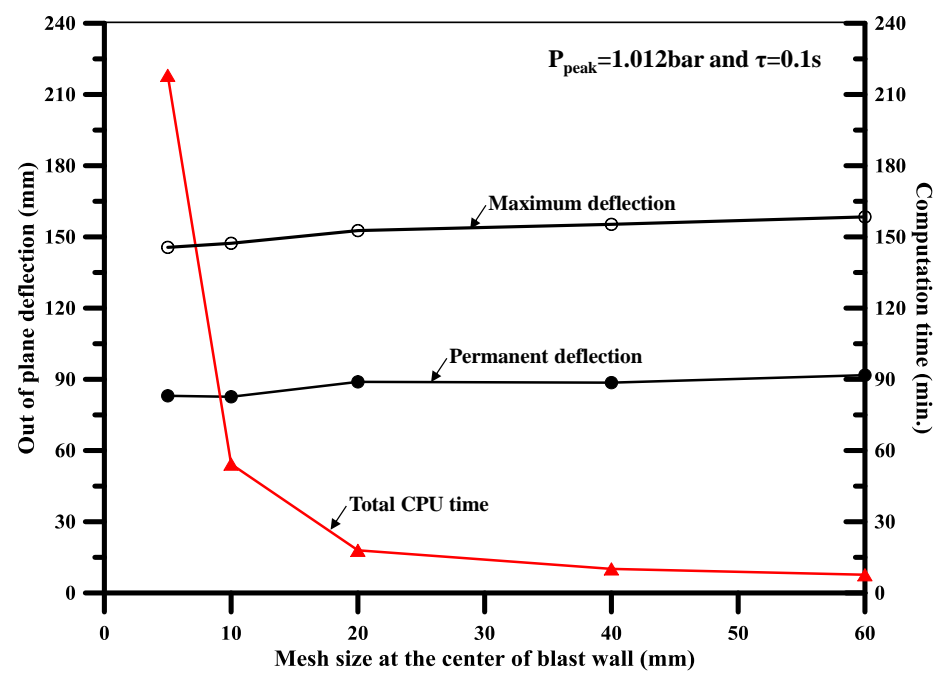

Figure 6. Mesh convergence of the blast walls.

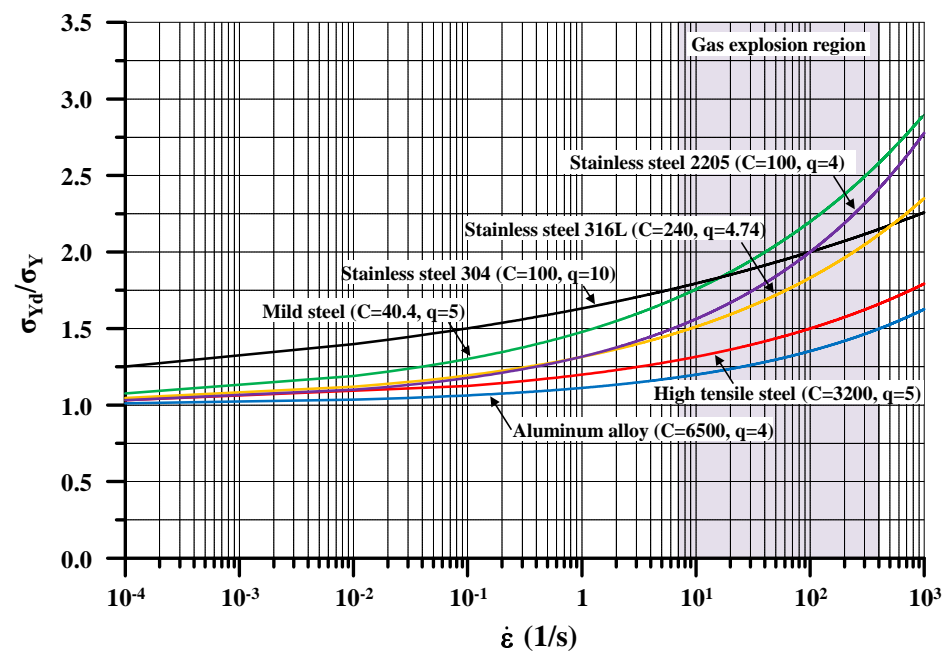

Figure 7. Dynamic yield strength (normalized by the static yield strength) plotted versus strain rate. 


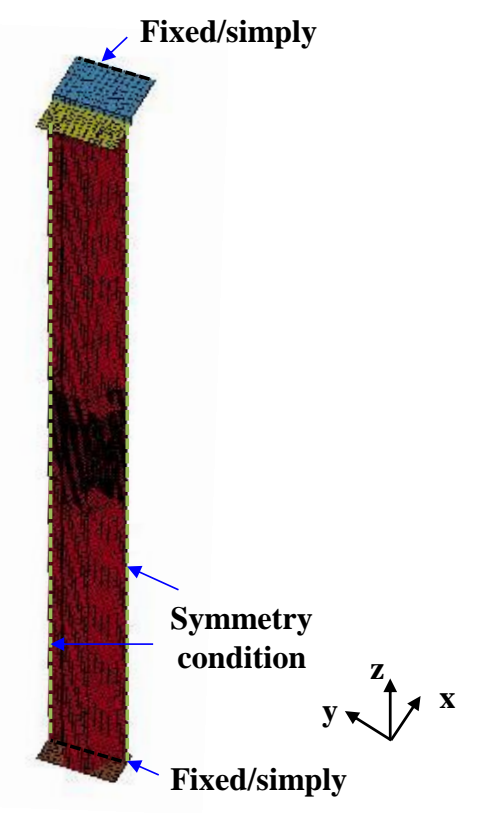

Figure 8. Applied boundary conditions.

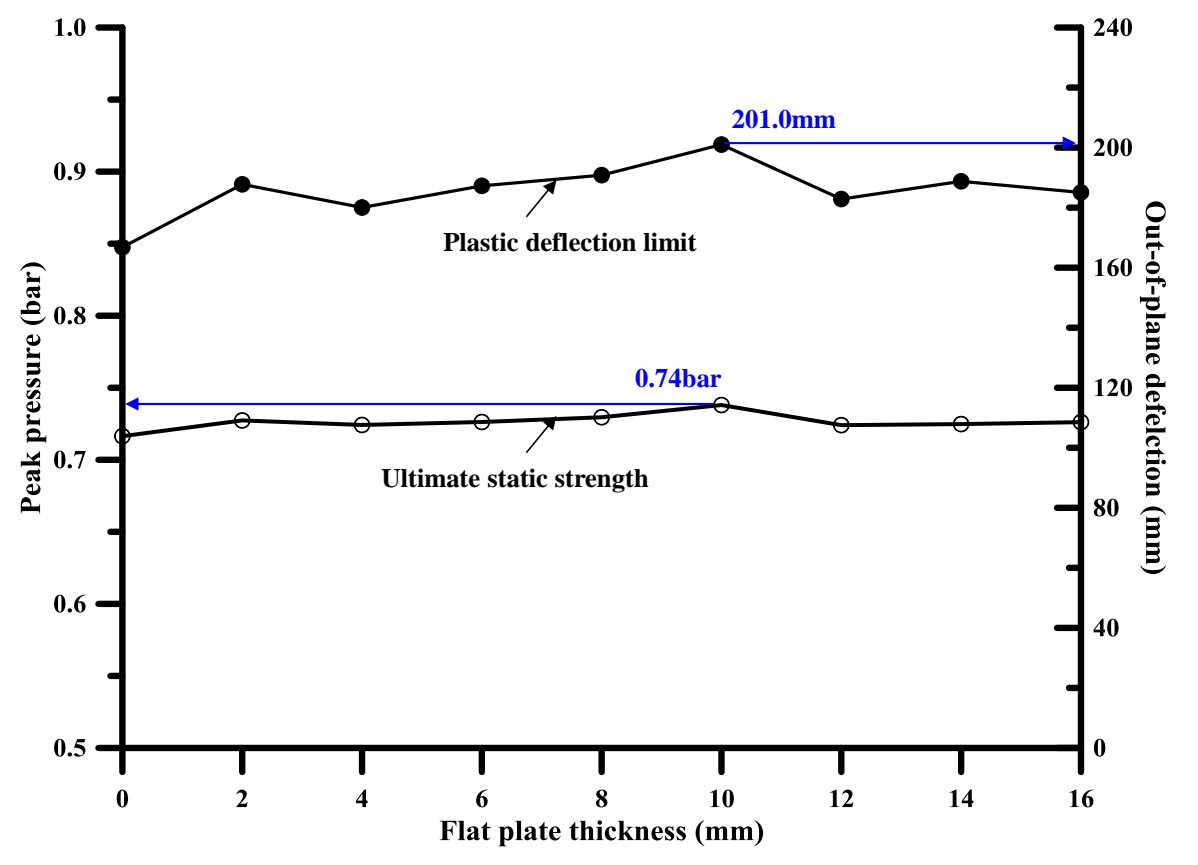

Figure 9. Static push-over analysis of unstiffened and stiffened blast wall. 


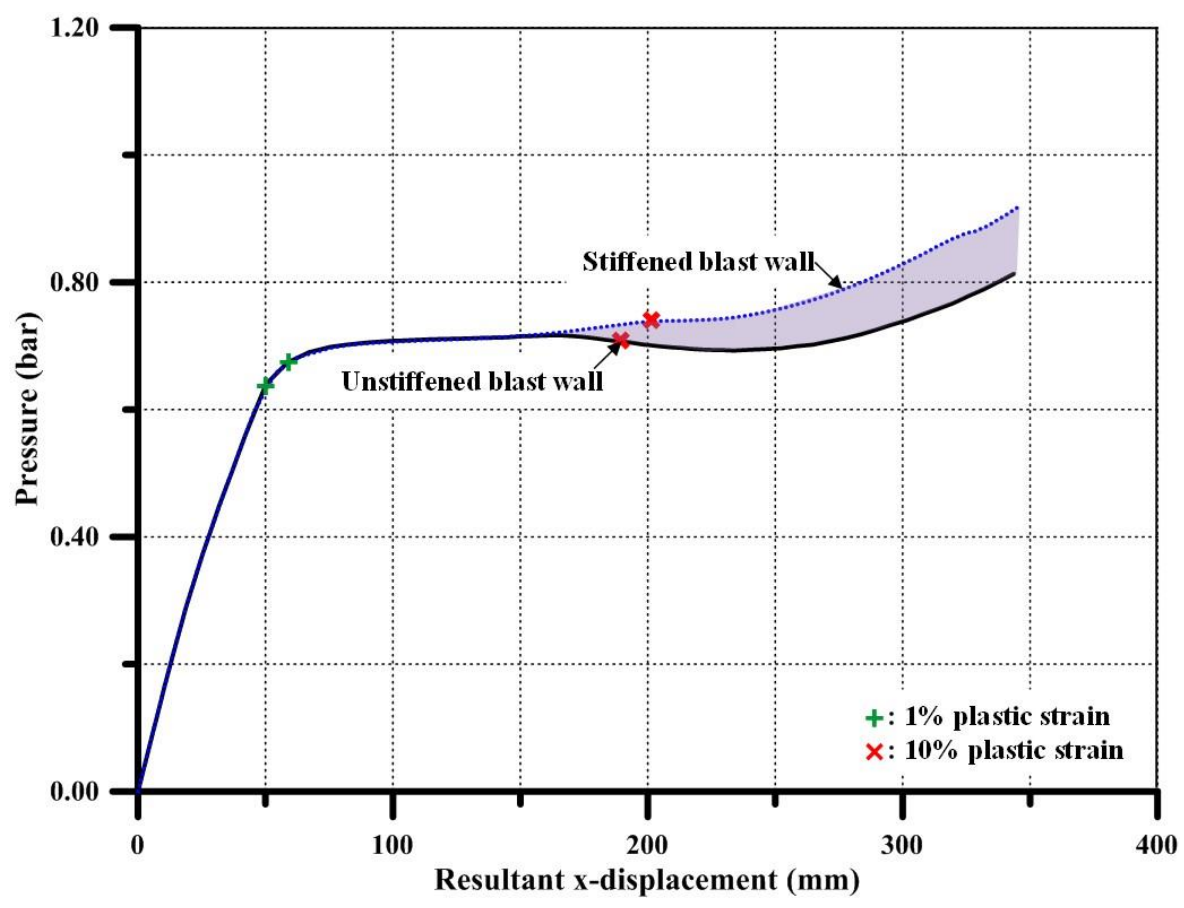

Figure 10. Comparison of pushover curves between stiffened and un-stiffened blast wall.

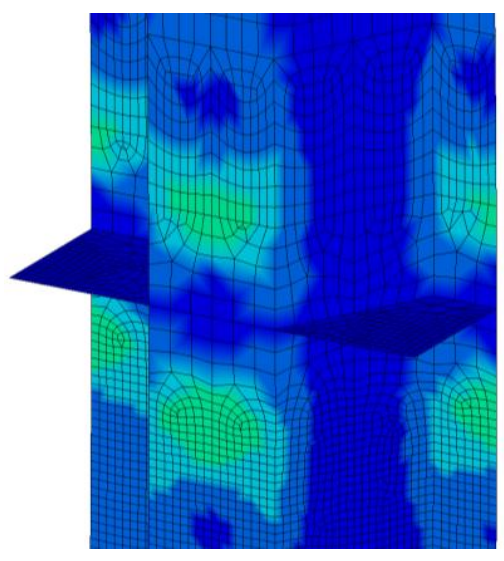

(a) Wall damage at $1 \%$ plastic strain

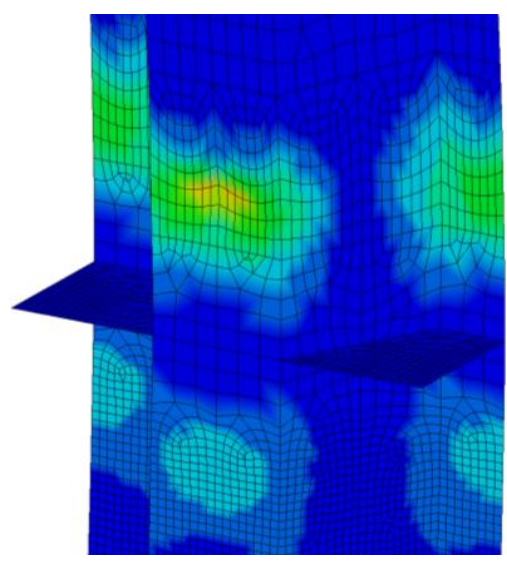

(b) Wall damage at $10 \%$ plastic strain

Figure 11. Nonlinear static responses of stiffened blast wall. 


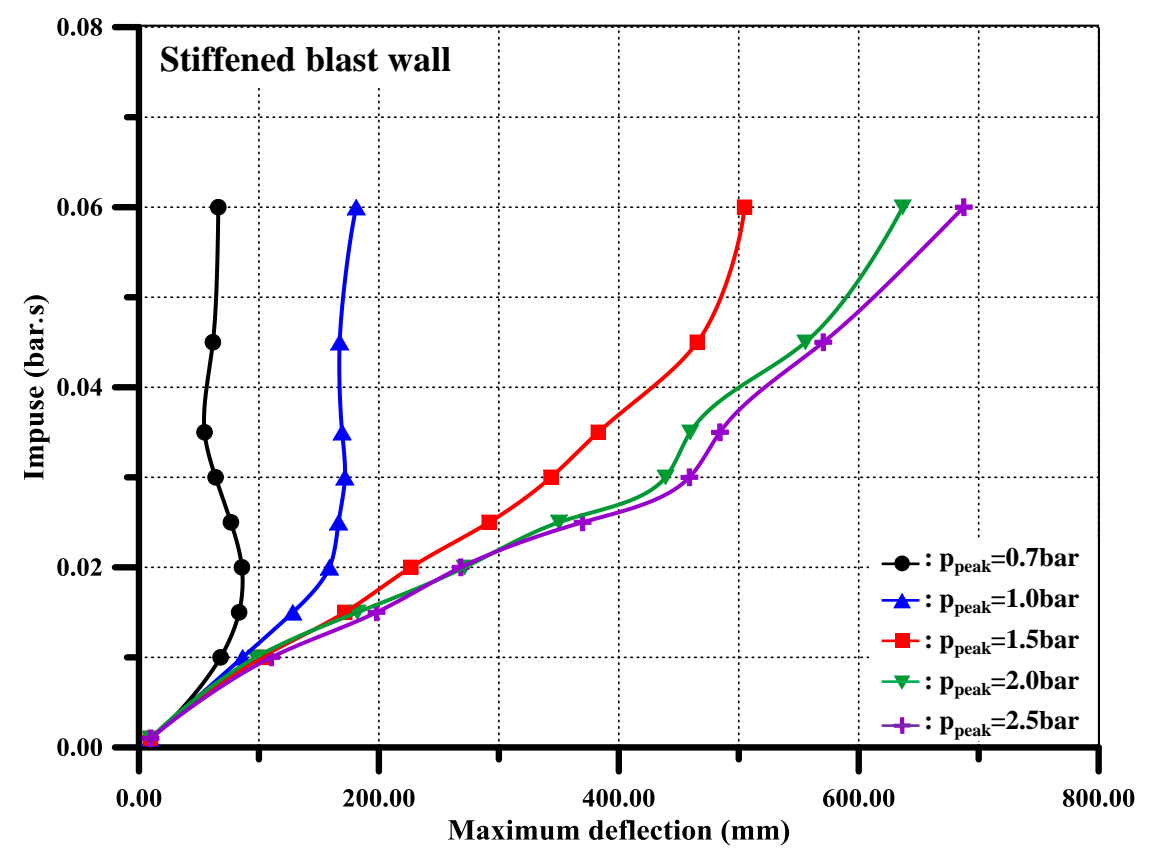

Figure 12. Maximum deflection of stiffened blast walls with varying peak pressure.

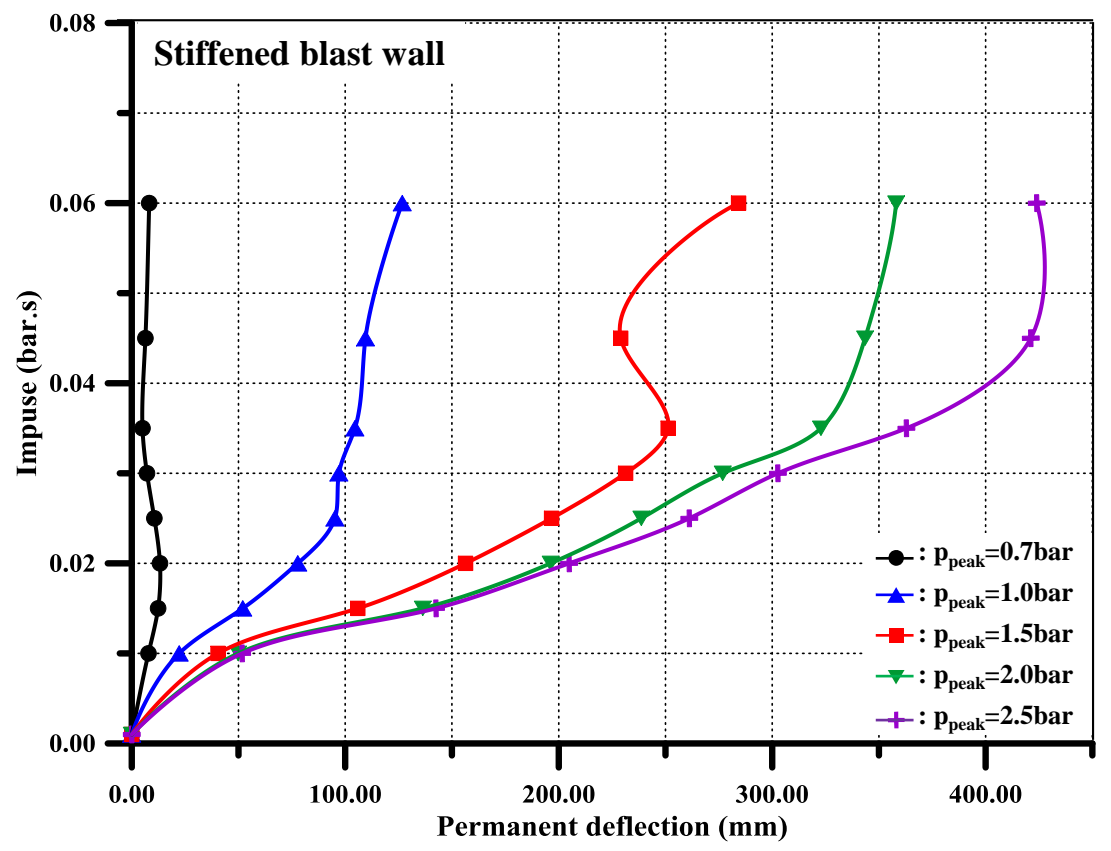

Figure 13. Permanent deflection of stiffened blast walls with varying peak pressure. 


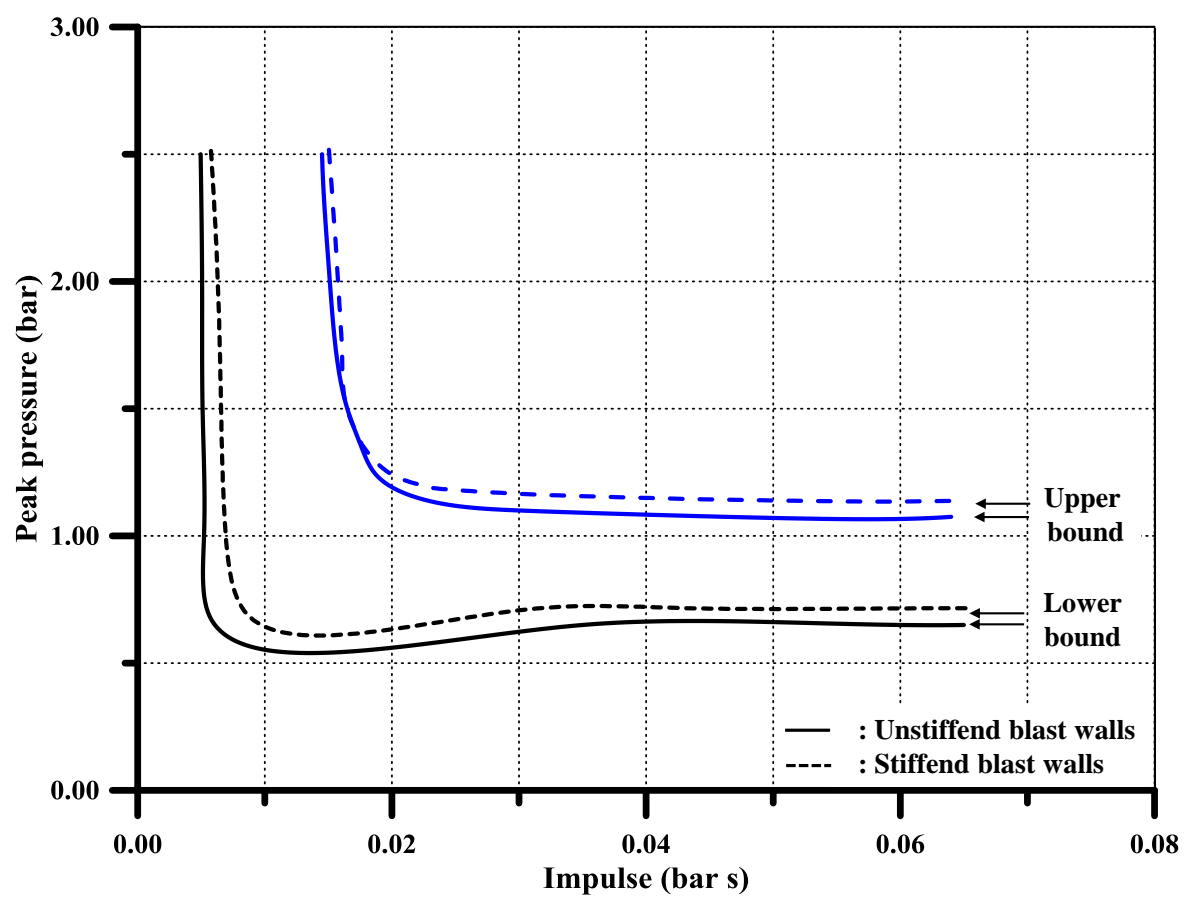

Figure 14. Proposed Pressure-Impulse curves of stiffened blast walls.

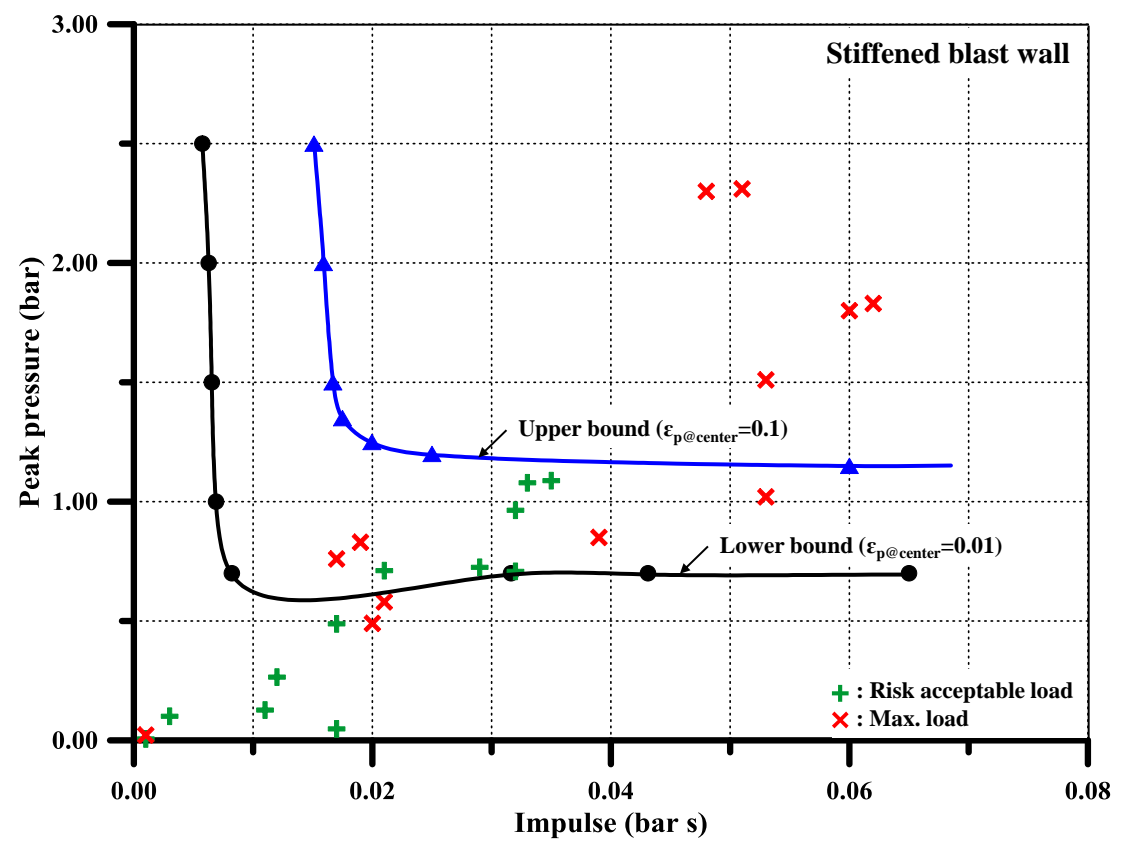

Figure 15. Proposed Pressure-Impulse curves of stiffened blast wall with specific explosion load level.

\section{Tables}


Table 1. Structural damage for stiffened the blast walls.

\begin{tabular}{|c|c|c|c|c|c|c|c|}
\hline \multirow{2}{*}{\multicolumn{2}{|c|}{ Location }} & \multicolumn{3}{|c|}{$\begin{array}{l}\text { Risk acceptable load level } \\
\left(10^{-4} \text { year }\right)\end{array}$} & \multicolumn{3}{|c|}{ Pessimistic case } \\
\hline & & $\begin{array}{c}\text { Pressure } \\
\text { (bar) }\end{array}$ & $\begin{array}{c}\text { Impulse } \\
\text { (bar·s) }\end{array}$ & $\begin{array}{c}\text { Structural } \\
\text { damage }\end{array}$ & $\begin{array}{c}\text { Pressure } \\
\text { (bar) }\end{array}$ & $\begin{array}{c}\text { Impulse } \\
\text { (bar's) }\end{array}$ & $\begin{array}{c}\text { Structural } \\
\text { damage }\end{array}$ \\
\hline \multicolumn{2}{|c|}{$\begin{array}{c}\text { Under the solid } \\
\text { process deck }\end{array}$} & 0.127 & 0.011 & Elastic & 0.490 & 0.020 & Elastic \\
\hline \multicolumn{2}{|c|}{$\begin{array}{c}\text { Solid process } \\
\text { deck }\end{array}$} & 0.725 & 0.029 & Plastic & 1.800 & 0.060 & Failure \\
\hline \multicolumn{2}{|c|}{$\begin{array}{l}\text { Above the solid } \\
\text { process deck } \\
\text { around primary } \\
\text { structures }\end{array}$} & 0.964 & 0.032 & Plastic & 1.830 & 0.062 & Failure \\
\hline \multicolumn{2}{|c|}{$\begin{array}{c}\text { Above the } \\
\text { middle process } \\
\text { deck }\end{array}$} & 0.711 & 0.021 & Plastic & 1.510 & 0.053 & Failure \\
\hline \multicolumn{2}{|c|}{$\begin{array}{l}\text { Under the top } \\
\text { process deck } \\
\text { around primary } \\
\text { structures }\end{array}$} & 1.088 & 0.035 & Plastic & 2.310 & 0.051 & Failure \\
\hline \multicolumn{2}{|c|}{$\begin{array}{l}\text { Top process } \\
\text { deck }\end{array}$} & 1.079 & 0.033 & Plastic & 2.300 & 0.048 & Failure \\
\hline \multicolumn{2}{|c|}{$\begin{array}{l}\text { Above the top } \\
\text { process deck }\end{array}$} & 0.101 & 0.003 & Elastic & 0.580 & 0.021 & Plastic \\
\hline \multirow{3}{*}{$\begin{array}{l}\text { Blast } \\
\text { walls }\end{array}$} & $\begin{array}{c}\text { Forwar } \\
\text { d }\end{array}$ & 0.048 & 0.017 & Elastic & 0.850 & 0.039 & Plastic \\
\hline & Aft. & 0.265 & 0.012 & Elastic & 0.830 & 0.019 & Plastic \\
\hline & $\begin{array}{l}\text { Pipe } \\
\text { rack } \\
\text { side } \\
\end{array}$ & 0.488 & 0.017 & Elastic & 0.760 & 0.017 & Plastic \\
\hline \multicolumn{2}{|c|}{$\begin{array}{c}\text { Large } \\
\text { cylindrical } \\
\text { vessels }\end{array}$} & 0.708 & 0.032 & Plastic & 1.020 & 0.053 & Plastic \\
\hline \multicolumn{2}{|c|}{$\begin{array}{l}\text { Equipment and } \\
\text { piping on the } \\
\text { solid process } \\
\text { deck (drag) }\end{array}$} & 0.006 & 0.001 & Elastic & 0.022 & 0.001 & Elastic \\
\hline
\end{tabular}


Table 2. Effective plastic strain for connections.

\begin{tabular}{|c|c|c|c|c|c|c|c|c|c|c|}
\hline \multirow{2}{*}{$\begin{array}{c}I \\
(\text { bar } \cdot s)\end{array}$} & \multicolumn{2}{|c|}{$p_{\text {peak }}=0.7 \mathrm{bar}$} & \multicolumn{2}{|c|}{$p_{\text {peak }}=1.0 \mathrm{bar}$} & \multicolumn{2}{|c|}{$p_{\text {peak }}=1.5 \mathrm{bar}$} & \multicolumn{2}{|c|}{$p_{\text {peak }}=2.0 \mathrm{bar}$} & \multicolumn{2}{|c|}{$p_{\text {peak }}=2.5 \mathrm{bar}$} \\
\hline & $\varepsilon_{p @ \text { center }}$ & $\varepsilon_{p @ e n d}$ & $\varepsilon_{p @ \text { center }}$ & $\varepsilon_{p @ e n d}$ & $\varepsilon_{p @ \text { center }}$ & $\varepsilon_{p @ e n d}$ & $\varepsilon_{p @ \text { center }}$ & $\varepsilon_{p @ e n d}$ & $\varepsilon_{p @ \text { center }}$ & $\varepsilon_{p @ \text { end }}$ \\
\hline 0.001 & 0.00000 & 0.00000 & 0.00000 & 0.00000 & 0.00000 & 0.00000 & 0.00000 & 0.00000 & 0.00000 & 0.00000 \\
\hline 0.010 & 0.00632 & 0.00551 & 0.01297 & 0.00954 & 0.01675 & 0.01473 & 0.01615 & 0.01829 & 0.01848 & 0.01832 \\
\hline 0.015 & 0.00771 & 0.00598 & 0.02505 & 0.01228 & 0.03981 & 0.01772 & 0.03938 & 0.02139 & 0.03943 & 0.02264 \\
\hline 0.020 & 0.00842 & 0.00528 & 0.03419 & 0.01357 & 0.03901 & 0.02120 & 0.04650 & 0.02732 & 0.04626 & 0.03083 \\
\hline 0.025 & 0.00595 & 0.00337 & 0.03129 & 0.01445 & 0.03569 & 0.02956 & 0.04789 & 0.04289 & 0.04955 & 0.04718 \\
\hline 0.030 & 0.00691 & 0.00123 & 0.02798 & 0.01392 & 0.03524 & 0.04684 & 0.04471 & 0.07078 & 0.05504 & 0.08514 \\
\hline 0.035 & 0.00198 & 0.00182 & 0.02526 & 0.01465 & 0.03101 & 0.05733 & 0.04120 & 0.07165 & 0.05940 & 0.11703 \\
\hline 0.045 & 0.00309 & 0.00232 & 0.02092 & 0.01400 & 0.03940 & 0.06710 & 0.04974 & 0.07267 & 0.06382 & 0.13879 \\
\hline 0.060 & 0.00393 & 0.00213 & 0.02118 & 0.01389 & 0.03114 & 0.07124 & 0.05923 & 0.08798 & 0.06537 & 0.12587 \\
\hline
\end{tabular}

